\title{
A HISTÓRIA DA EDUCAÇÃO NA FORMAÇÃO DE PROFESSORES: UMA REFLEXÃO DA PRÁTICA PEDAGÓGICA
}

\author{
A history of education in teacher training: \\ a reflection of teaching practice
}

\begin{abstract}
RESUMO Este relato de experiência objetiva refletir sobre a prática pedagógica histórica como elemento indissociável da própria ação educativa, por meio de cursos para a Formação Inicial e Continuada. As reflexões que aqui se apresentam são resultados das ações desenvolvidas no Projeto de Extensão "Teoria e Prática: união sem fronteiras entre Universidade e Educação Básica para a prática cidadã na periferia de Londrina", que fez parte do Programa Universidade Sem Fronteiras. O problema central da pesquisa foi o de como possibilitar a reflexão da prática pedagógica por intermédio da História da Educação. A abordagem teórica-metodológica foi a crítico-dialética e os escritos de autores que discutem a História da Educação, por poder refletir acerca das ações educativas na realidade escolar. Trata-se, portanto, da exposição das ações realizadas no projeto, a fim de relatar a experiência das discussões a respeito da História da Educação brasileira com os alunos bolsistas, graduandos do Curso de Pedagogia da Universidade Estadual de Londrina, egressos do Curso de Pedagogia e com os professores da Educação Básica, especificamente, das escolas atendidas pelo Projeto de Extensão. Como resultados apresentados, pudemos perceber pelas discussões feitas ao fim do projeto que houve reflexão e mudança por parte dos professores participantes, valorizando, assim, a prática pedagógica.
\end{abstract}

PALAVRAS-CHAVE: FORMAÇÃ̃ INICIAL. FORMAÇÃO CONTINUADA. HISTÓRIA DA EDUCAÇÃo. PRÁtICAS PEDAGóGICAS. FormaÇÃo dE PROFESSORES.

\begin{abstract}
This report of experience aims to reflect on the historical pedagogical practice as an inseparable element of the educational action itself, through courses for Initial and Continuing Formation. The reflections presented here are the results of the actions developed in the Extension Project "Theory and Practice: union without frontiers between University and Basic Education for the citizen's practice in the outskirts of Londrina", which was part of the University Without Borders Program. The central problem of the research was how to enable the reflection of pedagogical practice through the History of Education. The theoretical-methodological approach was the critic-dialectic and the writings of authors who discuss the History of Education, for being able to reflect on the educational actions present in the school reality. It is therefore the presentation of the actions carried out in the project, in order to report the experience of the discussions on History of Brazilian Education with the scholarship students, graduates of the Pedagogy Course of the State University of Londrina, graduates of the Pedagogy Course and with The teachers of the Basic Education, specifically, of the schools served by the Extension Project. As results presented, we could perceive by the discussions carried out at the end of the project that there was reflection and change on the part OF THE PARTICIPATING TEACHERS, THUS VALUING THE PEDAGOGICAL PRACTICE.
\end{abstract}

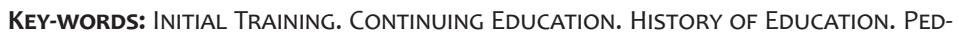
AGOGICAL PRACTICES. TEACHER TRAINING.

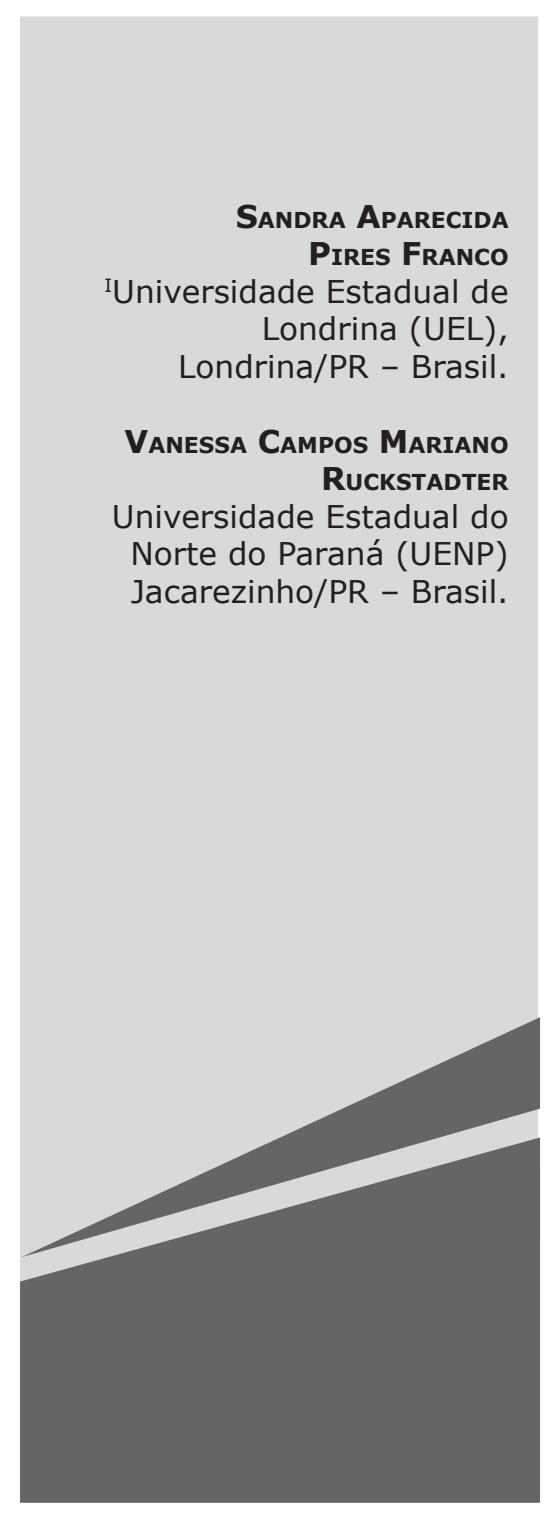




\section{INTRODUÇÃO}

Ser membro de uma comunidade humana é situar-se em relação ao seu passado (ou da comunidade), ainda que apenas para rejeitá-lo.

- Eric J. Hobsbawm

Em tempos de mudanças aceleradas, sobretudo no que concerne às Tecnologias da Informação e Comunicação (TICs), retornar ao passado parece algo ultrapassado e a ser superado nos cursos de Formação de Professores. Tanto na Formação Inicial quanto na Formação Continuada, os educadores são pressionados a saberem lidar com "novos" recursos, em um movimento que poderíamos classificar como neotecnicismo, que permeia o discurso pedagógico e educativo na contemporaneidade. No entanto, a epígrafe citada aponta a direção para uma discussão acerca do sentido da História na formação crítica do educador.

Este relato de experiência objetiva discutir o sentido do passado como elemento na Formação Inicial e Continuada de professores. Tal texto envereda pelo caminho de defesa da reflexão da prática pedagógica como elemento indissociável da própria ação educativa. As reflexões que aqui se apresentam estão pautadas na abordagem crítico-dialética e são resultados das ações desenvolvidas no Projeto de Extensão "Teoria e Prática: união sem fronteiras entre Universidade e Educação Básica para a prática cidadã na periferia de Londrina", que fez parte do Programa Universidade Sem Fronteiras. Pensar a formação de professores numa abordagem histórico-crítica sugere o uso da História da Educação pois o Materialismo Histórico e Dialético prima pelo conhecimento histórico sistematizado e elaborado por outros homens para a análise do presente (SAVIANI e DUARTE, 2012).

Trata-se, por essa razão, da apresentação das ações realizadas no projeto, a fim de relatar a experiência das discussões sobre História da Educação brasileira e a participação no projeto com os alunos bolsistas, graduan- dos do Curso de Pedagogia da Universidade Estadual de Londrina, egressos do Curso de Pedagogia e com os professores da Educação Básica, especificamente, das escolas atendidas pelo Projeto de Extensão.

Primeiramente, foi apresentada pela pesquisadora HE (referência específica para a professora da IES de História da Educação) uma discussão acerca da importância da junção teoria e prática e, especialmente, a importância da História da Educação como componente curricular dos cursos de Formação de Professores, no viés do Materialismo Histórico e Dialético. Na sequência, foi exposta pela pesquisadora D (referência à professora da IES de Didática) em linhas gerais a proposta do projeto, para, em seguida, analisar o sentido do passado na Formação de Professores a partir das ações realizadas tanto com os alunos bolsistas (Formação Inicial) quanto com os professores da Educação Básica das escolas atendidas pelo projeto (Formação Continuada).

A concepção da formação de professores que fundamentou o projeto de extensão realizado foi a histórico-crítica. Após a análise da História da Educação brasileira, a pesquisadora D da referida Universidade que compunha o projeto, adentrou com a elaboração de planos de unidade pautados na Pedagogia Histórico-Crítica, pois ambas as pesquisadoras afirmaram que apreender a realidade em suas múltiplas determinações é o caminho para a obtenção do pensamento teórico. Planejar o ensino é uma possibilidade de dar aos indivíduos a apropriação dos conteúdos históricos que se expressam em conceitos. A simples utilização da Pedagogia Histórico-Crítica sem a apropriação da valorização de como os homens agiram durante a humanidade em termos de ações educacionais pode levar o professor ao risco de culminar numa leitura reducionista em relação às proposições da Pedagogia Histórico-Crítica.

\section{O QUE É HISTÓRIA DA EDUCAÇÃO?}

Não há História da Educação sem a mobilização rigorosa dos instrumen- 
tos teóricos e metodológicos da investigação histórica. Mas também não há História da Educação sem um pensamento e um olhar específicos sobre a realidade educativa e pedagógica.

- António Nóvoa

Para dar fundamentos teóricos para os professores envolvidos no Curso de Extensão, foi levantado pelas pesquisadoras o questionamento do que seria História da Educação. Os professores nesse momento começaram a expor: P1 comenta que "são fatos históricos acontecidos no passado", P4 menciona que "são documentos encontrados por pesquisadores". Para poder expor para o grupo de professores das escolas envolvidas, a pesquisadora $\mathrm{HE}$ explicou que, ao longo do século XX, houve o processo de consolidação da área de História da Educação na academia brasileira, especialmente após a segunda metade do século. Explanou que há três vertentes nesse processo de constituição da área: os trabalhos desenvolvidos no Instituto Histórico e Geográfico Brasileiro (IHGB); as pesquisas elaboradas para atender às necessidades advindas da implantação da disciplina nos Cursos das Escolas Normais e os estudos iniciados com a criação dos Programas de Pós-Graduação em Educação na década de 1960 (VIDAL; FARIA FILHO, 2003).

Numa constante busca por expor acerca da História da Educação, a pesquisadora $\mathrm{HE}$ comentou que, com o surgimento do campo disciplinar no Brasil, começaram a ter origem os Cursos Normais. Apresentou que as disciplinas dos Cursos Normais tinham cunho moralizante e objetivavam estudar os grandes educadores em uma perspectiva de exemplos a serem imitados pelos professores em formação. A História da Educação era estudada como Genealogia. Havia, sobremaneira, a aproximação com a Filosofia, em uma perspectiva de estudo de ideias pedagógicas a serem reproduzidas no presente.

Diante desses fatos, a pesquisadora $\mathrm{HE}$ faz a seguinte indagação: Mas qual a importância em um contexto atual em manter nos currículos de Formação de Professores e continuar a defender a presença da História da Educação na Formação Continuada? A pesquisadora $\mathrm{HE}$, ancorada na defesa realizada pelo historiador português da educação, Nóvoa (2005; 1999), destacou alguns aspectos a serem considerados.

À princípio, a pesquisadora HE relata que a História permitia identificar mudanças, mas, principalmente permanências. Isso auxiliava na identificação de práticas pedagógicas naturalizadas como históricas e, portanto, passíveis de mudança. As pesquisadoras HE e $D$, então, pensando nas ações desenvolvidas nesse Projeto de Extensão, ao olhar os problemas das escolas e identificar as possíveis causas dos baixos índices nas avaliações, acreditaram que a ciência da História possibilitava entender por meio da produção material dos homens as relações sociais temporalmente definidas. Estudar a História da Educação permitia compreender, a partir dessas relações, os processos educacionais em diferentes épocas históricas.

A importância que as pesquisadoras $\mathrm{HE}$ e D atribuíam aos estudos das memórias da Educação consistiam em afirmar que "[...] é a contribuição dada em exercitar nosso pensamento, nossas opções, tomadas de decisão sobre os agoras da educação de nosso tempo" (STEPHANOU; BASTOS, 2004, p. 15). Ainda mais na área de Educação, em que a novidade sempre é aclamada, mesmo que essa novidade seja somente uma retomada de ideias e ações pedagógicas separadas da contemporaneidade muitas vezes por séculos ou até mesmo milênios.

Destacaram, então, que conhecer o passado para entender as relações sociais existentes em cada época é de suma importância, sobretudo no campo educacional, uma vez que Educação é também uma construção social. Entender a novidade como retomada, muitas vezes evita que simplesmente se dobrem, enquanto educadores, às novidades com entusiasmo, acreditando que se está diante de novas teorias para a Educação, quando na verdade são apenas uma retoma- 
da de ideias antes desenvolvidas por outros estudiosos.

Em tempos de mudança acelerada em setores flexíveis da sociedade, perceberam a evocação de um ideal de inovação também na prática educativa. $\mathrm{O}$ entusiasmo diante da novidade, sobretudo no que diz respeito aos métodos pedagógicos, está presente no cotidiano escolar. Pensar na História da Educação como a possibilidade de cultivar um "saudável ceticismo”, conforme aponta Nóvoa (2005), contribui para que diante das supostas inovações pedagógicas o educador aja de modo reflexivo. Assim, a pesquisadora HE vai relatando que uma primeira e fundamental tarefa da História da Educação é a de fornecer ao educador subsídios teóricos para a compreensão de sua prática e, por conseguinte, sua transformação em um movimento dialético.

A pesquisadora HE divulga, aos professores e graduandos participantes do Curso de Extensão, que o olhar histórico permite a compreensão de que a inovação não deve ser entendida simplesmente como mudança, ruptura, mas também, como tentativa de manter a sociedade. Cada geração utiliza o passado como padrão para o presente, mas reproduz a tradição somente até onde seja possível. Assim, mesmo as sociedades mais tradicionais aceitam mais facilmente inovações em setores flexíveis, como a tecnologia, por exemplo, mas não em setores mais inflexíveis como a organização social e a ideologia, ou sistema de valores (HOBSBAWM, 1998). Dessa maneira, estar diante do passado educacional faz que o educador possa refletir sobre sua prática pedagógica e não apenas ver os "novos" métodos e recursos como prioridade em sua formação.

Segundo a pesquisadora $\mathrm{HE}$, o passado deixa de ser padrão para o presente quando a mudança social acelera ou transforma a sociedade para além:

Quando a mudança social acelera ou transforma a sociedade para além de um certo ponto, o passado deve cessar de ser o padrão do presente, e pode, no máximo, tornar- -se modelo para o mesmo. 'Devemos voltar aos caminhos de nossos antepassados' quando já não os triIhamos automaticamente, ou quando não é provável que o façamos. Isso implica uma transformação fundamental do próprio passado. Ele agora se torna, e deve se tornar, uma máscara para a inovação, pois já não expressa a repetição daquilo que ocorreu antes, mas ações que são, por definição, diferentes das anteriores. Mesmo quando se tenta realmente retroceder o relógio, isso não restabelece de fato os velhos tempos, mas meramente certas partes do sistema formal do passado consciente, que agora são funcionalmente diferentes [...] (HOBSBAWM, 1998, p. 25-26).

A legitimação de propostas de inovações acontece de poucas maneiras:

Ela pode ser disfarçada como retorno ou redescoberta de alguma parte do passado erroneamente esquecida ou abandonada, ou pela invenção de um princípio anti-histórico de força moral superior prescrevendo a destruição do presente/ passado, como, por exemplo, uma revelação religiosa ou profecia (HOBSBAWM, 1998, p. 24).

Diante dessas afirmações, a pesquisadora $\mathrm{D}$ menciona uma segunda tarefa desse campo disciplinar: formar indivíduos que são sujeitos de sua prática. Ao ter acesso ao passado social formalizado da educação, o educador pode compreender seu lugar enquanto sujeito do processo educacional.

[...] embora a alta tecnologia possa ser usada, ainda que não haja novos avanços, sem pensamento original, a ciência necessita de ideias. Mesmo a sociedade mais contraintelec- 
tual hoje tem maior necessidade de pessoas com ideias, e de ambientes nos quais elas se desenvolvam. Podemos afirmar, com toda a segurança, que esses indivíduos também terão ideias críticas sobre a sociedade e o ambiente em que vivem (HOBSBAWM, 2012, p. 235).

O educador não pode ser reduzido a um executor de técnicas, mas sim como aquele que possui ideias. Ainda que o Projeto de Extensão aqui apresentado tivesse como uma das ações a elaboração de planos de ensino e de oficinas com alunos, uma das preocupações de ambas as pesquisadoras foi colocar os educadores e os alunos bolsistas diante do legado educacional brasileiro. Assim, podem ser mediadores do conhecimento, não apenas técnicos executores de pacotes de instrução (LIBÂNEO, 2009). Afirmam que o domínio da técnica não substitui o domínio do conhecimento, o que inclui o conhecimento histórico que possibilita ao educador situar-se em relação ao seu passado e ao passado de sua comunidade escolar.

Em um diálogo constante, solicitam que os professores e bolsistas participantes percebam que, a partir do trecho em destaque no início deste texto, pode-se complementar as afirmações do historiador inglês Hobsbawm (1917-2012), no sentido de ponderar que para um educador situar-se em relação ao passado educacional ele deve situar-se em relação ao passado de sua comunidade escolar e compreender suas práticas como parte de um contexto maior. Isso significa também que a História da Educação ajuda a situar o educador em relação ao seu próprio passado, pois "[...] fornece aos educadores um conhecimento do passado coletivo da profissão, que serve para formar a sua cultura profissional" (NÓVOA, 1999, p. 13). Não se trata de afirmar que a partir de tal conhecimento os educadores tenham práticas mais eficazes, mas sim, de acreditar que ao conferir um sentido ao passado de sua prática pedagógica o educador se torna mais crítico e reflexivo e vislumbra em suas atividades pedagógicas uma prática cidadã visando a emancipação.

A pesquisadora $\mathrm{HE}$ acredita que olhar para a História da Educação permite a ampliação da memória e da experiência de educadores em suas escolhas e possibilidades pedagógicas. Principalmente, porque "[...] revela que a educação não é um 'destino', mas uma construção social, o que renova o sentido da ação quotidiana de cada educador" (NÓVOA, 1999, p. 13). O sentido do passado permite questionar e não apenas legitimar práticas pedagógicas naturalizadas do presente. Permite ainda ao educador perceber-se enquanto sujeito de sua prática pedagógica.

As pesquisadoras $\mathrm{HE}$ e $\mathrm{D}$ afirmam que a prática pedagógica, quando relacionada à História da Educação, possibilita ao professor uma maior abrangência do contexto social, político, econômico e cultural em que os seus alunos estão incluídos, pois, na perspectiva do Materialismo Histórico e Dialético, essa prática pedagógica necessita de um professor consciente de suas ações e repleto de intencionalidades. Nessa perspectiva de análise, o processo da prática pedagógica se substancia historicamente e que se realiza por ações concretas, presentes nas relações sociais (SAVIANI e DUARTE, 2012).

Diante desse contexto social, a pesquisadora $\mathrm{D}$ menciona que para a prática pedagógica, o acesso aos conteúdos clássicos e científicos como condição para a formação humana é imprescindível. Clássico é, então, o que resistiu ao tempo, tendo uma validade que extrapole o momento em que foi formulado. Permanece como referência para as futuras gerações que se apropriam das objetivações humanas produzidas. O processo de formação humana é aquele que se apossa "das objetivações humanas produzidas ao longo da história" (SAVIANI e DUARTE, 2012, p. 34).

Afirma ainda que pensar uma teoria marxista da educação para uma pedagogia marxista precisa, primeiramente, pensar em educar seres humanos na contemporaneidade. Pensar isso significa pensar sobre a essência da prática pedagógica. 


\section{TEORIA E PRÁTICA: UNIÃO SEM FRONTEIRAS}

As ações do Projeto de Extensão objetivaram o resgate da cidadania e autoestima das comunidades escolares com baixo Índice de Desenvolvimento da Educação Básica (IDEB). As escolas situadas na periferia de Londrina e em um de seus distritos compõem uma região que constitui um bolsão de pobreza em um dos municípios com o Índice de Desenvolvimento Humano - Municipal (IDH-M) mais alto do Estado do Paraná.

O Curso de extensão pretendeu contribuir para o alargamento da compreensão a respeito de fatores sociais, políticos, econômicos, históricos e dos conteúdos de ensino trabalhados pelos professores das referidas escolas. Esse trabalho foi realizado por meio de algumas ações como debates, reflexão, elaboração e produção de materiais de apoio com as escolas e não somente para as escolas. Interessante destacar que os professores se apropriaram da didática da Pedagogia Histórico-crítica e elaboraram planos de unidade para as suas próximas aulas.

O trabalho foi conduzido relacionando as atividades didáticas com as reflexões da História da Educação brasileira nos fundamentos históricos das ideias filosóficas que embasam os processos de ensino, especialmente aqueles que defendem a emancipação dos indivíduos por meio do conhecimento científico.

O caráter interdisciplinar dessa proposta pedagógica constituiu-se a partir da aproximação das áreas de História da Educação e Didática do Departamento de Educação da Universidade Estadual de Londrina (UEL), e da aproximação da Universidade com a Educação Básica Pública desse município.

Essa aproximação embasou a metodologia do projeto que propôs a História como ferramenta de reflexão crítica dos processos de ensino e aprendizagem, por conseguinte, da realidade escolar, a fim de modificar práticas e superar as dificuldades das escolas no tocante à organização do trabalho pedagógico. Visou ainda a inserção social dos sujeitos dessas escolas e de suas comunidades. Por meio do projeto, esperava-se contribuir mais que para a simples superação matemática de um índice e sim com a reflexão constante e identificação das possíveis causas do baixo rendimento para a formação de indivíduos emancipados pelo conhecimento e que efetivem a prática da cidadania por meio do resgate da autoestima. Nesse sentido, podemos considerar que o objetivo foi atingido, pois, no momento em que desenvolvemos as primeiras ações, especialmente no início do Curso de Extensão realizado sobre a História da Educação Brasileira, percebemos a partir das discussões com os professores, por exemplo, uma contextualização da escola e um esforço em compreendê-la tanto em seu contexto local quanto em sua relação com o passado educacional brasileiro.

As escolas que foram alvos da intervenção aqui proposta obtiveram as seis menores notas do (IDEB) no município nos últimos quatro anos. São elas: quatro Colégios Estaduais de Ensino Fundamental e Médio e uma Escola Estadual de Ensino Fundamental. O índice é calculado a partir da média do desempenho dos alunos na Prova Brasil e no Saeb, e do índice de aprovação dos alunos. Em 2009, a maior nota das escolas escolhidas foi 3,0. Isso motivou as pesquisadoras a desenvolver este trabalho, uma vez que a Universidade tem um compromisso social com a comunidade à qual pertence.

Esse projeto realizou ações junto à comunidade escolar, visando a valorização da escola como espaço de discussão, reflexão e busca de soluções, a fim de transformar o cotidiano escolar e, consequentemente, promover a inserção social das escolas no bairro. A proposta foi promover a junção de duas áreas compreendidas muitas vezes pelos professores em formação e mesmo pelos professores que já atuam, essencialmente uma como teórica - no caso da História da Educação; e, a outra como prática - no caso da Didática. Assim, em conjunto com os graduandos e recém-formados, o projeto buscou promover a integração entre a Universidade, as escolas e a comunidade, além de contribuir para a futu- 
ra prática dos professores em formação e daqueles que iniciam sua atividade na docência.

A integração foi um importante aprendizado para os alunos bolsistas e, em especial, para os discentes do Curso de Pedagogia. Nesse sentido, a contribuição ampliou-se, ultrapassando os limites dos muros das escolas e da Universidade e rompendo as fronteiras entre o conhecimento científico e a cultura escolar.

O projeto teve quatro eixos norteadores. Primeiramente, foram realizadas reflexões teóricas aliadas às realidades das escolas com o pesquisador $\mathrm{HE}$ e o pesquisador $\mathrm{D}$, os bolsistas, equipe pedagógica e professores, a fim de promover a integração da equipe do projeto e das escolas.

A partir das visitas às escolas, o objetivo foi elaborar, conjuntamente, estratégias de intervenção (planos de unidade) para com os pais e os alunos a partir das necessidades específicas das escolas. O projeto encontrou nas escolas a existência de um trabalho em andamento e que não foi desconsiderado. Partiu-se da premissa de que todos os envolvidos no projeto eram sujeitos no processo e não apenas objetos de análise.

Depois, foram realizadas reuniões entre as pesquisadoras $\mathrm{HE}$ e D e os alunos bolsistas. $\mathrm{Na}$ sequência, foram feitas as discussões com a equipe pedagógica e professores das escolas. Essas discussões aconteceram no formato de Curso de Extensão, e o relato a seguir narra a experiência em dois momentos do projeto. Primeiro, na discussão sobre a História da Educação e o sentido do passado na formação de professores com os alunos bolsistas e, em um segundo momento, as discussões realizadas com os professores e equipe pedagógica das escolas alvos desse plano de unidade.

A discussão com os alunos bolsistas iniciou-se a partir da exibição e discussão do documentário Pro dia Nascer Feliz, do diretor João Jardim. O principal objetivo foi identificar problemas em comum com as escolas visitadas e, especialmente, discutir que ir ao passado só se justifica como tentativa de compreensão do presente. Dessa forma, as discussões iniciais tiveram como resultado a compreensão de que a História da Educação pode ser uma importante ferramenta para subsidiar a identificação de problemas na escola hoje, especialmente, na compreensão da escola como inserida em um contexto político, social, cultural e econômico. A escola é parte da sociedade e só pode ser compreendida em sua relação com sua época e lugar.

Foram discutidos alguns textos com o objetivo de analisar qual o sentido do passado educacional para a Formação de Professores. A principal referência foi a discussão do capítulo intitulado O sentido do passado, que compõe a coletânea de textos publicada no Brasil com o título Sobre História, do historiador inglês Hobsbawm (1998). O foco de discussão foi, sobretudo, a História como possibilidade de compreensão do presente, mas também como legitimadora de mudanças e adequações. Também discutiram-se que não se pode rejeitar o passado pois disso decorre um problema: entender a inovação, a mudança como inevitável ou como fator de desenvolvimento. Direcionaram essa discussão para a compreensão das escolas, em um momento em que se procurava identificar as possíveis causas do baixo desempenho das escolas e da perda da autoestima por parte de alunos e professores. O novo não significa necessariamente o melhor, ou ainda, algo inevitável. Essas discussões possibilitaram o embasamento teórico para a posterior elaboração de planos de unidade e metodologias de intervenção junto às escolas, considerando sempre professores e alunos como sujeitos desse processo.

Por fim, analisamos a função da escola e do professor na sociedade atual, utilizando como referência o livro Adeus Professor, Adeus Professora, de José Carlos Libâneo (2009). Foi dada atenção especial a uma discussão sobre a importância da escola e da atuação dos professores com o objetivo de valorização de ambos no contexto atual.

Em um segundo momento, iniciaram-se as discussões com os professores e equipes pedagógicas das escolas envolvidas. A mediação aconteceu em formato de Curso de Extensão organizado na Universidade Estadual 
de Londrina, a fim de verificar qual o contato dos professores e equipes pedagógicas com o campo disciplinar. Todos os presentes relataram suas experiências com a História da Educação. Havia professores de distintas áreas e a maioria disse que não teve contato com a História da Educação em sua formação inicial. Aqueles que tiveram, foram os alunos de Cursos de Pedagogia.

Foram discutidos os momentos da História da Educação e da escolarização no Brasil, com a finalidade de situar os educadores em relação ao passado educacional brasileiro. Também foi realizado um panorama histórico das abordagens pedagógicas, a fim de compreendê-las em seus contextos, até chegarmos à abordagem Histórico-Crítica, que embasou a elaboração dos planos de aula e as propostas de oficinas e intervenções nas escolas. Houve participação ativa dos professores presentes no curso.

Participar desse processo de discussão e mediação com os alunos bolsistas, em sua Formação Inicial, os alunos egressos, bem como, com os educadores em Formação Continuada, permitiu a integração entre a Universidade e a Educação Básica, um dos objetivos das ações desenvolvidas pelo Projeto de Extensão. Desenvolver estratégias de identificação das possíveis causas dos baixos índices, estudar a educação brasileira em diferentes épocas e as abordagens educacionais em uma perspectiva histórica possibilitaram a participação ativa dos bolsistas, das pesquisadoras HE e D, bem como dos professores e equipe pedagógica das escolas em todo o processo.

Essa primeira ação do projeto atingiu o objetivo de promover a integração da equipe do projeto e das escolas para elaborar em conjunto estratégias de intervenção para com os pais e os alunos, bem como, planos de unidade a partir das necessidades específicas das escolas. Tal ação também ofereceu a todos os envolvidos o contato com a História da Educação e suas transformações, o que promoveu a reflexão acerca das consequências emergentes da atual Educação que vivenciamos em nossas escolas e sociedade.
Como uma forma de acompanhar o processo de aprendizagem dos profissionais da educação que estão sendo atendidos no projeto maior, sujeitaram-se questionar alguns professores a fim de verificar a importância e a diferença que o Curso de Extensão pode fazer até então.

Os professores entrevistados eram especialistas nas áreas de: Língua Portuguesa, Biologia, Educação Artística, Educação Física, Ciências e Matemática. Sendo alguns professores do Ensino Fundamental I e II, outros do Ensino Médio.

A primeira pergunta foi: $O$ curso de extensão tem contribuído para o processo de formação continuada de vocês?

P1 respondeu que: "Com certeza, acreditamos que qualquer curso que o professor possa fazer mesmo que tenha concluído um curso de pós-graduação, será extremamente importante, pois há essa troca com companheiros de outras áreas de conhecimento. Pelas próprias discussões que a gente tem feito com o pessoal, tanto com os colegas da mesma escola tanto com os das outras escolas, tem nos proporcionado novas ideias e contribuindo com as que já tínhamos".

P2: "Tem feito a gente rever muitas práticas, descobrir qual é a pedagogia que está vigente e tem feito a gente repensar a maneira de abordar nossos conteúdos que é uma coisa que com o passar do tempo você vai deixando para trás, porque no dia a dia você não repensa muito isso e é bom dar uma parada para rever".

A segunda pergunta foi: Professores, em seus processos de formação, vocês tiveram contato com conteúdos que foram abordados neste curso de extensão, como História da Educação e Práticas Pedagógicas?

$\mathrm{P} 4$ respondeu: "Não durante nossas graduações, porém em alguns cursos, como especializações ou de formação continuada é que temos visto o básico em relação a estes conteúdos. Portanto, este curso está sendo muito importante, pois é um conhecimento novo, é algo que pode ser agregado a cada disciplina para enriquecer nosso trabalho em sala de aula". 
A terceira pergunta foi: Vocês acreditam que na educação possa haver mudanças significativas se professores como vocês buscarem participar cada vez mais de projetos como este desenvolvidos pelas universidades?

P11 respondeu: "Sim, se houver o dia que a gente deixar de acreditar que vai ter mudanças na educação, a gente tem que parar de trabalhar. A educação é um organismo vivo, então ela tem que estar constantemente sendo abastecida para ela mudar, se não, nós não vamos crescer enquanto educadores e nem nossos educandos vão conseguir modificar a situação em que eles vivem. Por ela ser constante, temos que sempre buscar e implantar novos conhecimentos".

P15 respondeu: "Quando o educador se dispõe em fazer um curso como esse, a entrar em contato com professores de outras áreas, a trocar informações, a fazer um trabalho compartilhado, entrar nessa área ampla da educação - porque quem estuda suas disciplinas, acaba afastando um pouco da área da educação - então só tem como contribuir sim. Participando da elaboração destes projetos (planejamentos) está sendo muito enriquecedor, porque você acaba trocando com os companheiros, trocando com vocês que vem com todo esse conteúdo para gente, então é importante sim".

De maneira geral, de acordo com depoimentos dos bolsistas, a participação no projeto, o contato com os educadores inseridos em diversos contextos sociais e educacionais proporcionou aos professores muitos ganhos e aprendizagens, além de permitir o aprimoramento dos conhecimentos acerca da Perspectiva Histórico-Crítica, da importância do histórico da Educação e do planejamento de aula. Para comprovação, seguem os depoimentos dos professores $\mathrm{P} 4$ e P6:

Bom dia a todos e a todas, meu nome é Adriana, sou professora de língua portuguesa do colégio estadual de Paiquerê, estava conversando com as meninas agora pouquinho, eu estou aqui na universidade desde mil novecentos e noventa e seis, hoje eu sou doutoranda, estou no ultimo semestre do doutorado em ensinos literários, e eu vejo todo mundo comentando sobre essa angustia que a gente não aprende nada, falta multa coisa nos (bancos) e realmente não vão aprender, eu to concluindo um doutorado aqui na universidade e, é a pratica mesmo, é a sala de aula, é a escola, é isso aqui que a gente ta vivendo que na realidade vai definir o nosso caminho, a universidade é um recurso né, tem muito, a gente aprende muito, mas a pratica mesmo vai acontecer nesse tipo de encontro que nós estamos fazendo aqui neste momento, é também participei do projeto em duas fazes, na primeira faze toda teoria, agora, e com certeza foi extremamente enriquecedor, é essa troca, isso que a gente ta fazendo aqui, essa coisa de experiência é realmente muito forte, e é isso que realmente fica... é... os alunos... eu na realidade comecei a aplicação do projeto, e eu tive que parar porque eu to em licença, licença (premium) e não pude recusar como estou na faze final de qualificação e defesa, inclusive minha qualificação foi ontem e já estou qualificada, posso ir pra defesa né e então eu não tinha como recusar, tinha que ser agora porque a coisa é bem complicada né, mas eu comecei com eles a aplicação do projeto, e o retorno realmente foi muito bom, nós optamos por fazer um trabalho entre as disciplinas de historia, arte e língua portuguesa, trabalhamos com a semana de arte moderna realmente né, semana de vinte e dois, englobando todos esses aspectos, e o engraçado é que nós começamos essas atividades sem avisar, sem comentar com eles que ia ser uma coi- 
sa em conjunto, mas eles foram se ligando que, poxa essas professoras estão cercando a gente, então eles começaram perceber que a coisa tava andando em conjunto, então mesmo participando só do inicio, aplicando só uma parte, eles tinham essa noção, de que, eles logo perceberam que a coisa tava caminhando junto, e aí uns alunos (diziam): Professora, a professora Gisele ta falando de tal coisa, pera aí, se não falou disso já? É verdade... então aí gente foi conversando, então devagar eles foram percebendo, que a coisa tava interligada, e realmente ficou muito rico, eles fizeram em determinado momento, eles fizeram a prova da Gisele e vieram me falar: Professora, sabe aquele texto que vc trabalhou lá do (Policarpo Quaresma) né um pouquinho antes lá o pré modernismo, ajudou pra caramba professora, foi muito legal e tal, então, esse retorno foi positivo. É eu acho que alguém já comentou aqui, é nós professores somos realmente, ficamos sempre um pouquinho com o pé atrás em relação ao planejamento, eu não vou mentir, e aprender a trabalhar isso como unidade, a trabalhar (uma unidade) quando fala em planejamento se fala: caramba, vou ter que fazer isso com todos os meus conteúdos? não, da pra gente agregar, da pra fazer de uma forma mais fechada, mais junto, e dessa forma é produtivo, é logico que as coisas tem que ser revistas no meio do percurso, mudanças acontecem, mais é possível sim, é não vou mentir não, que quando eu entrei aqui né comecei a participar da primeira etapa eu entrei com um pézinho atrás sim, ah! De novo vai falar sobre planejamento, eu tenho certeza que um monte de gente entrou dessa forma, ah eu vou fazer mas tudo bem, planejamento não funciona, mas funciona, na realidade é um objeto pra que nós mesmos nos organizemos né, você vai se organizar, pra sua aula ser organizada, pro seu ano, seu semestre, bimestre ser organizado, nós temos que começar isso na gente, e foi isso que eu aprendi aqui, foi realmente muito importante, essa troca, ficar sabendo o que ta acontecendo, até mesmo pra nós lá da escola, isso nos aproximou muito né, nós já somos um grupo bem coeso, bem unido, mas aproximou mais ainda em todos os aspectos, e fora isso conhecer as experiências de outras escolas, de outras pessoas, trabalhar com esse grupo que é dez, foi muito bacana, eu agradeço essa oportunidade e tenho certeza que todos nós vamos sair daqui com um crescimento muito bom em termos de aprendizagem mesmo, estar no banco da universidade é muito bom, é bom trocar essas experiências tanto que estou aqui desde noventa e seis, mas é isso, obrigada pela oportunidade (P4).

Bem, minha experiência com o projeto foi de grande valia, né. E esses dias atrás estava comentando ai com as meninas que eu tive duas experiências, assim, interessantes: uma foi extremamente positiva e a outra foi extremamente negativa. É assim... como é que foi negativa? Não pelo planejamento em si, mas as vezes acho que pela maturidade da turma, as vezes, que não conseguiu acompanhar a proposta do trabalho. Mas assim, de uma certa forma houve, né, mesmo neste trabalho que é negativo, houve um monte de interrogações que ficou no aluno, que o aluno começou a fazer também, né, aquilo que a gente 
acha que é negativo, pode se tornar extremamente positivo que faça com que você passa a, é, repense, né, a estratégia do seu trabalho, né. Eu fiz essa experiência com uma série, o sétimo ano, e o aluno não conseguiu, é, atender as minhas expectativas, as vezes nem é as expectativas do aluno, mas a expectativa do professor, né. Eu esperava que sempre ia acontecer uma coisa e acontecia ao contrário, e de repente eu fiquei as vezes mais que a metade do tempo da aula levantando perguntas para o aluno e o aluno só olhando pra mim, e, aquela coisa como sempre, né, com aquela cara de paisagem.

E eu fiz um comparativo com o terceiro ano, do ensino médio, porque é, assim, é, são bem mais maduros, e eu tive uma resposta extremamente positiva, né, quando eu comecei com a proposta de trabalho, que eu introduzi, eu, sem falar nada sobre o que eu estava fazendo, eles começaram a questionar algumas coisas. Isso nem sobre o assunto que eu to trabalhando que é globalização, né. Bom, o terceiro ano se interessou mais, participaram um pouco mais, acho que tivemos ai uma participação mais efetiva, pelo menos no início do trabalho, porque não fechei ainda essa proposta de trabalho ainda com eles, porque essa semana teríamos aula quarta e sexta e ainda não...aconteceram alguns percalços na escola e não terminamos o trabalho. Mas, assim, extremamente positivo, porque, fez com que eu atingisse muito mais fácil o meu aluno do ensino médio, né, eu acho que o nível de dar aula subiu, subiu um pouco mais, né, não que a gente não planejasse antes mas o planejamento era diferente, né, e fez com que meu nível de conversa com o aluno fosse diferente, né, eu não fiquei só preso aquele conteúdo que tá lá no livro ou o contexto, né, teve uma abertura de horizontes, novos assuntos foram introduzidos dentro do conteúdo que a gente pode aproveitar bastante, principalmente o conhecimento do aluno, né, não só o conhecimento que vamos levar, né, mas aquilo que o aluno tem, né, e nos conseguimos extrair bastante coisa e conseguimos com a geografia demonstrar vários elementos que vai estar presente no dia a dia que eles não davam sentido por exemplo, na, com a matéria, vendo o conteúdo em si, eles não conseguiam perceber a geografia no seu dia a dia, e isso colaborou bastante para eles perceberam o quanto a geografia faz parte da vida deles no dia a dia (P6).

Pelos dizeres dos professores citados, pode-se constatar que foram diferentes experiências vivenciadas no decorrer do processo, tanto em relação à apropriação do conhecimento que envolve a Pedagogia Histórico-Crítica, quanto em relação ao contato com os educadores envolvidos no projeto e na própria relação entre a equipe organizadora, pois tiveram a oportunidade de trabalhar com a organização, elaboração e aplicação de planos de unidade, permitindo assim um contato mais direto com a realidade em sala de aula.

Essas contribuições foram de grande relevância para a Formação Profissional, tendo em vista que muito se discute na Formação Inicial sobre os Fundamentos da Educação, mas, os momentos de contato com a realidade escolar são escassos, assim, uma das grandes contribuições foi a de conhecer concretamente a realidade da escola pública. Outra contribuição relevante foi em relação à aplicação da teoria e prática. Foram muitos os momentos de discussões teóricas acerca da realidade escolar atrelada à prática pedagógi- 
ca, assim, as discussões teóricas eram em função de uma realidade escolar que necessitava de uma intervenção planejada, desse modo, a teoria servia de guia planejada e consciente da ação prática.

As ações do projeto proporcionaram uma percepção quanto às relações existentes para além do imediato e do aparente que permeiam a problemática educacional. Dessa forma, pode-se concluir que este trabalho foi de extrema relevância para a formação das futuras educadoras, pois permitiu um valioso aprendizado, vivências e experiências.

Vale destacar que, por meio dos estudos teóricos desenvolvidos no projeto, bem como, por intermédio do contato com a realidade educacional das instituições de ensino atendidas pelo projeto, foi possível realizar um intercâmbio entre Universidade e Escola Básica, propiciando uma melhor reflexão sobre o processo educativo, acerca das muitas adversidades vivenciadas no meio escolar; dos processos pedagógicos e, principalmente, das dificuldades encontradas pelo corpo docente em relação ao planejamento de ensino e à atual condição em que as escolas públicas se encontram.

Ultrapassar os limites da Universidade e adentrar nos espaços escolares e poder compartilhar com os educadores as suas angústias, as decepções, as alegrias e dificuldades foram de suma importância para a formação da identidade profissional, chamando a atenção para a importância do educador ter uma base teórica consistente e definida, pois as adversidades que encontramos além dos limites da Universidade serão tantas, que somente um profissional devidamente preparado e consciente das dificuldades, da sua função e responsabilidade conseguirá desenvolver um trabalho capaz de efetivar a humanização do sujeito.

Diante do exposto, pode-se destacar que as ações dos professores devem garantir uma educação de qualidade, possibilitando ao aluno condições de tornar-se consciente e autônomo nesse processo, por meio de uma organização e sistematização do ato de estudar, como uma rotina em sua vida, compreen- dendo-se melhor enquanto sujeito histórico e social, analisando e refletindo sobre o ato de ensinar e aprender, num contexto histórico e emancipatório.

Portanto, a educação escolar deve ser pensada no sentido de educar para que os sujeitos possam ter condições de efetivamente participar nas lutas sociais, propondo a transformação social e superando a ordem imposta pelos dominantes, tendo a História da Educação como ponto de partida.

\section{CONSIDERAÇÕES FINAIS}

A proposta neste relato de experiência foi contribuir com reflexões referentes à realidade que tais escolas se encontram, e então, compreender como proceder com os conhecimentos científicos sem que haja rupturas com o contexto social. Para tanto, recorreu à História da Educação para poder contextualizar e proporcionar caminhos de superação pautados na história social de um espaço, ou seja, da instituição escolar.

Como observou-se, a História se faz necessária no que condiz à educação presente, sendo que muitos dos acontecimentos de hoje são consequências de um passado político e social que mantinham suas visões na formação de indivíduos unilaterais.

Portanto, é preciso ter conhecimento sobre as realidades vividas a fim de propor mudanças sociais por meio da educação. Com base em um referencial pautado na perspectiva Histórico-Crítica, o projeto teve como intenção contribuir com a complementação nas formações de educadores, com o interesse de inseri-los na realidade escolar que vivenciam por meio da compreensão do processo histórico.

A partir dessa apropriação, visando uma prática concreta à realidade, o projeto instrumentalizou-se por meio da realização de momentos de reflexões teóricas e de momentos práticos, a fim de conquistar resultados e mudanças significativas aos problemas pontuados pelas mesmas, chegando também a transformações sociais na comunidade. Sabe-se que tal processo não é imediatista, tendo, portanto, o objetivo de fazer um trabalho de 
conscientização dos professores envolvidos, a fim de que a perpetuação de tal aprendizado seja consequência do processo de aprendizado desses professores.

Destacou-se que as ações do projeto também buscaram explicitar a importância do conhecimento teórico enquanto guia da prática pedagógica para a concretização de ações que transformem a realidade escolar, ou seja, buscou-se pela práxis educativa desenvolver ações de reflexões e discussões que contribu- íssem para o despertar dos educadores para a especificidade do ato educativo enquanto processo de humanização do sujeito.

Assim, ao compreender as inúmeras dificuldades enfrentadas pelos educadores no contexto escolar, e sendo a Universidade um espaço de ensino, pesquisa e extensão, viu-se a importância de se integrar as escolas e comunidades a fim de contribuir para a futura prática dos professores em formação e daqueles que iniciam sua atividade na docência.

\section{REFERÊNCIAS}

HOBSBABWM, E. J. Tempos Fraturados. São Paulo: Companhia das Letras, 2013.

. Sobre História. São Paulo: Companhia das Letras, 1998.

LIBÂNEO, J. C. Adeus professor, adeus professora? Novas exigências educacionais e profissão docente. São Paulo: Cortez, 2009.

NÓVOA, António. Apresentação. In: STEPHANOU, Maria; BASTOS, Maria Helena Camara (Org.). Histórias e Memórias da Educação no Brasil: Vol. II- Século XIX. Editora Vozes. Petrópolis, RJ, 2005, p. 9-13.

. Apresentação. In: CAMBI, F. História da Pedagogia. São Paulo: FEU, 1999, p. 11-16.

SAVIANI, Dermeval e DUARTE, Newton (Orgs.). Pedagogia Histórico-Crítica e luta de classes na educação escolar. Campinas: Autores Associados, 2012.

VIDAL, D.; FARIA FILHO, L. M. História da Educação no Brasil: a constituição histórica do campo (1880-1970). Revista Brasileira de História, v. 23, n. 45, jul. 2003, p. 37-70.

\section{DADOS DAS AUTORAS}

\section{SANDRA APARECIDA PIRES FRANCO}

Doutorado em Letras pela Universidade Estadual de Londrina. Professora adjunto do Departamento de Educação da Universidade Estadual de Londrina, na área de Didática e professora da Programa de Pós-Graduação em Educação.Londrina/PR - Brasil.sandrafranco26@hotmail.com

\section{VANESSA CAMPOS MARIANO RUCKSTADTER}

Doutora em Educação pela Universidade Estadual de Maringá. Professora Adjunta do Colegiado de Pedagogia do Centro de Ciências Humanas e da Educação da Universidade Estadual do Norte do Paraná. Jacarezinho/PR - Brasil. vanessaruck@hotmail.com

Submetido em: 1-4-2015

Aceito em: 30-3-2017 